\title{
Eritrocitose primária em cão: relato de caso
}

[Primary erythrocytosis in dog: case report]

\author{
S. Gonçalves ${ }^{1}$, D. Reggiani ${ }^{2}$, M.B. Moreira ${ }^{2}$
}

${ }^{1}$ Universidade de Santo Amaro - Hemovet - São Paulo, SP

${ }^{2}$ Universidade Anhembi Morumbi - São Paulo, SP.

\begin{abstract}
RESUMO
A eritrocitose absoluta primária, também denominada de policitemia vera, é um distúrbio mieloproliferativo crônico de causa desconhecida, caracterizado pela proliferação clonal de células-tronco eritróides neoplásicas. Acomete cães de meia-idade entre seis e sete anos. As manifestações clínicas mais comuns são letargia, fraqueza, poliúria, polidipsia, sangramentos como epistaxe, hematúria, hematoemese, hematoquezia, até mesmo convulsões e ataxia. O diagnóstico é baseado em valores altos de hematócrito, geralmente acima de $70 \%$, excluindo-se as causas de eritrocitose secundária. As concentrações séricas de eritropoietina estão normais ou diminuídas. O tratamento consiste em flebotomia e administração de hidroxiuréia. Relata-se o caso de uma cadela, raça Bichon Frise, 11 anos, que, no início do quadro, apresentou hematócrito de $84 \%$, letargia, ataxia, mucosas congestas, cianose de língua, poliúria e polidipsia. Realizou-se o tratamento com hidroxiuréia durante oito anos, na dose de 15 a 30 $\mathrm{mg} / \mathrm{kg}$, a cada 24 horas, sem ocorrência de efeitos colaterais ou recidiva das manifestações clínicas.
\end{abstract}

Palavras-chave: cães, eritrocitose, hidroxiuréia

\begin{abstract}
Primary absolute erythrocytosis, also termed polycythemia vera, is a chronic myeloproliferative disorder of unknown cause. It is characterized by clonal proliferation of neoplastic erythroid stem cells. It affects middle-aged dogs between 6-7 years. The most common clinical manifestations are lethargy, weakness, polyuria, polydipsia, and bleeding such as epistaxis, hematuria, hematoemese, and hematochezia. Seizures and ataxia are also common. Diagnosis is based on high hematocrit values, generally above $70 \%$ excluding the causes of secondary erythrocytosis. Serum concentrations of erythropoietin are at a normal level or decreased level. Treatments consists of hydroxyurea and phlebotomy management. It is reported that case of female Bichon Frise, 11 years old who onset of the disease had a hematocrit of $84 \%$, lethargy, ataxia, congested mucous membranes, tongue cyanosis, polyuria and polydipsia. The treatment with hydroxyurea was performed for 8 years, at a dose of 15 to $20 \mathrm{mg} / \mathrm{kg}$, every 24 hours, without occurrence of side effects or recurrence of clinical manifestations.
\end{abstract}

Keywords: dogs, erythrocytosis, hydroxyurea

\section{INTRODUÇÃO}

Define-se eritrocitose como a elevação do número de hemácias circulantes (massa eritrocítica), representada hematologicamente pelo aumento do valor do hematócrito, ou seja, acima dos valores de referência para a espécie (Nitshe, 2004).

Atualmente, prefere-se o termo eritrocitose para a designação das anormalidades hematológicas referentes à elevação do hematócrito em cães e gatos à policitemia, que significa aumento do número de todas as células circulantes. A policitemia vera em humanos é caracterizada por eritrocitose acompanhada de neutrofilia e trombocitose. Entretanto, o número de neutrófilos e plaquetas em cães e gatos com policitemia vera é normal, logo o termo mais apropriado é eritrocitose primária (Villiers e Tappin, 2012).

Recebido em 21 de agosto de 2016 
A eritrocitose pode ser relativa, devido à diminuição do volume plasmático, ou absoluta. A eritrocitose absoluta pode resultar do aumento da concentração de eritropoietina (eritrocitose secundária) ou de uma doença mieloproliferativa denominada eritrocitose primária ou policitemia vera (Peterson e Randolph, 1982).

A eritrocitose relativa pode ter sua origem vinda de uma desidratação ou contração esplênica, sendo essa observada, com maior frequência, em equinos e gatos, por serem animais excitáveis, mas também pode ocorrer em situações de estresse, exercícios e dores severas (Nitshe, 2004).

A eritrocitose absoluta, caracterizada pelo aumento da quantidade de glóbulos vermelhos, ainda se divide em primária e secundária. A secundária tem como participação o aumento da produção de eritropoietina, que a deixa em alta concentração, subdividida em fisiologicamente apropriada e inapropriada (Nitshe, 2004).

A fisiologicamente apropriada acontece em decorrência de hipóxia tecidual, causada em pacientes com desvios vasculares direitaesquerda (tetralogia de Fallot e persistência do ducto arterioso) e doença pulmonar crônica (Moore e Stepien, 2001). Cães que vivem em altitudes elevadas também se enquadram nessa classificação (Nitshe, 2004). Já a inapropriada é caracterizada pelo aumento da concentração de eritropoietina, sem associação com hipóxia tecidual, geralmente associada às neoplasias renais e extrarrenais, como fibrossarcoma (Couto et al., 1989) e schwanoma (Villiers e Tappin, 2012).

Eritrocitose absoluta primária, mais conhecida como policitemia vera, é um distúrbio mieloproliferativo crônico caracterizado pela proliferação clonal de células-tronco eritróides neoplásicas, que requerem pouca ou nenhuma estimulação pela eritropoetina para clonagem, expansão, crescimento e diferenciação. Detectouse uma mutação no gene JAK2 em cães com policitemia vera semelhante à de humanos. Essa mutação leva à ativação da quinase responsável pela elevação do hematócrtio (Beurlet et al., 2011).

As manifestações clínicas da eritrocitose são secundárias à viscosidade aumentada do sangue. devido ao número excessivo de hemácias. Capilares e veias distendidas resultam em mucosas e pele eritematosas, podendo ocorrer cianose discreta em razão do fluxo sanguineo lento, diminuindo a perfusão tecidual e o transporte de oxigênio. Episódios de sangramento, como epistaxe, hematúria e hematoemese, podem ocorrer em decorrência da ruptura dos capilares.

Os três principais órgãos que são afetados pela hipervisosidade sanguínea são sistema nervoso central (SNC), rins e coração. Os principais sinais e sintomas do SNC são convulsões, letargia, fraqueza, ataxia, depressão e coma. Em decorrência de uma glomerulopatia, o animal apresenta poliúria e polidpsia (Quesnel e Kruth, 1992). Pode ser desenvolvida hipertrofia miocárdica devido à sobrecarga do músculo cardíaco. Anormalidades oculares, como hifemas, uveítes e hemorragia retiniana, também podem ser observadas (Gray et al., 2003).

O diagnóstico da eritrocitose primária é por exclusão, descartando-se todas as causas secundárias. O hematócrito é normamente bem elevado, em torno de 70 a $90 \%$ (Peterson e Randolph , 1982).

A eritrocitose relativa é a primeira a ser descartada após se reidratar o paciente, caracterizada pelo hematócrito elevado associada à concentração de proteína plasmática aumentada, indicando desidratação (Villiers e Tappin, 2012).

$\mathrm{Na}$ suspeita de eritrocitose secundária fisiologicamente apropriada, os exames de imagem, como radiografias torácicas, ecocardiogramas e eletrocardiogramas, conduzirão ao diagnóstico de doenças cardiopulmonares. A hemogasometria também é uma opção, em que a pressão parcial de oxigênio no sangue estará bem reduzida, juntamente com a redução acentuada da saturação arterial de hemoglobina (Moore e Stepien, 2001).

Neoplasias são investigadas por meio de ultrassonografia abdominal ou tomografia computadorizada, diante da suspeita de eritrocitose absoluta secundária inapropriada (Couto et al., 1989; Comazzi et al., 2000). 
Por fim, após exclusão das causas de eritrocitose secundária, é necessário observar a dosagem de eritropoetina, que irá concluir o quadro como uma eritrocitose primária, ou policitemia vera, quando sua concentração estiver baixa ou normal (Nitshe, 2004).

O tratamento da eritrocitose absoluta primária tem como objetivo diminuir o número de hemácias circulantes, para se obter a redução da viscosidade sanguínea. Esse objetivo é alcançado inicialmente por meio de flebotomias seriadas, removendo-se 10 a $20 \mathrm{~mL} / \mathrm{kg}$ e repondo-se o mesmo volume com solução cristaloide, a fim de minimizar os sinais e os sintomas (Villiers e Tappin, 2012).

A hidroxiuréia é o fármaco de eleição no tratamento da eritrocitose. A dose inicial é de $30 \mathrm{mg} / \mathrm{kg} /$ dia durante sete a 10 dias, seguida da dose de manutenção de $15 \mathrm{mg} / \mathrm{kg} /$ dia. A dose pode ser diminuída gradualmente, ou pode-se aumentar o intervalo, conforme a necessidade de cada paciente. Recomenda-se a realização de hemograma a cada quatro a oito semanas, devido ao caráter mielossupressivo dessa droga, cuja dose deverá ser ajustada de acordo com a contagem de neutrófilos do paciente. Os possíveis efeitos colaterais são anorexia, náusea, emese, mielossupressão e hipoplasia de medula óssea. (Nitshe, 2004).

O tempo de sobrevida de animais com eritrocitose primária é considerado longo, mais que dois anos tratados com hidróxiuréia, associada ou não à flebotomia (Villiers e Tappin, 2012).

\section{RELATO DE CASO}

Uma cadela da raça Bichon Frise, 11 anos, foi atendida com histórico de poliúria, polidipsia, cianose de língua e cansaço fácil havia duas semanas. Realizou-se hemograma, que revelou uma eritrocitose com hematócrito de $84 \%$. Ao exame físico, as mucosas estavam congestas, o animal apresentava-se taquipneico e com cianose de língua. Foram solicitadas função renal, hepática, urina I e radiografia torácica, sem alterações relevantes. $\mathrm{Na}$ ultrassonografia abdominal, o fígado apresentava-se com dimensões moderadamente aumentadas e arquitetura vascular com calibre moderadamente aumentado e baço com dimensões moderadamente aumentadas, sugerindo processo congestivo vascular. O mielograma revelou hiperplasia eritróide sem alterações morfológicas. A dosagem de eritropoietina foi de $1 \mathrm{mU} / \mathrm{mL}(1,8$ a $12,0 \mathrm{mU} / \mathrm{mL})$. A maioria dos hemogramas revelou também uma leucocitose $(18.000$ a $30.000 / \mu \mathrm{L})$.

Indicou-se o tratamento com hidroxiuréia, na dose de $30 \mathrm{mg} / \mathrm{kg} / 24 \mathrm{~h}$, por 60 dias, inicialmente, atingindo-se o hematócrito de 59\%. Nesse período, foram realizadas três flebotomias: dias um, sete e 50 em relação ao primeiro atendimento. A partir de então, reduziu-se a dose de hidroxiuréia para 15 a $30 \mathrm{mg} / \mathrm{kg} / 24 \mathrm{~h}$, completando-se oito anos de tratamento sem recidiva das manifestações clínicas e sem ocorrência de efeitos colaterais. As doses da hidroxiuréia foram ajustadas conforme as variações do hematócrito ao longo desses anos, permanecendo em torno de 55 a $60 \%$ (Fig. 1).

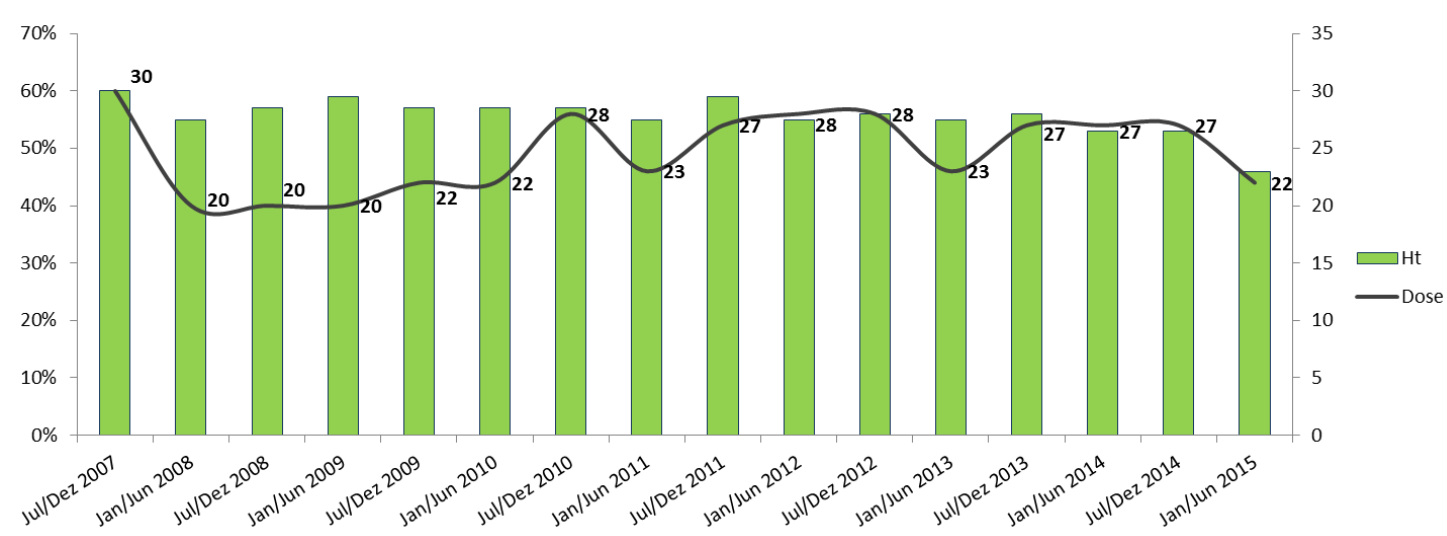

Figura 1. Variação do valor do hematócrito e doses de hidroxiureia $(\mathrm{mg} / \mathrm{kg})$ durante oito anos de tratamento de eritrocitose primária em cão. 


\section{DISCUSSÃO}

A policitemia vera é uma doença considerada rara na medicina veterinária (Holden, 1987), sem predisposição racial ou de sexo, entretanto a maioria dos cães acometidos são jovens ou de meia-idade (Peterson e Randolph, 1982; Wysoke e Heerden, 1990), com exceção de estudo de Fracassi et al. (2009), os quais a relataram em um cão com 12 anos. No caso documentado, o animal apresentava 10 anos, quando foi estabelecido o diagnóstico, contrariando a faixa etária da maioria dos relatos. Devido ao caráter raro, pode-se dizer que não há relatos suficientes para se estabelecer a predisposição racial ou sexual (Wysoke and Heerden, 1990).

Alguns sinais clínicos em cães com policitemia vera incluem letargia, mucosas hiperêmicas, anorexia, perda de peso, poliúria e polidipsia, depressão, hematúria e outros sinais do sistema nervoso central (Wysoke and Heerden, 1990). O animal do caso relatado apresentava o histórico de poliúria e polidipsia, juntamente com cansaço fácil e cianose de língua, porém, no exame físico, também foi constatada taquipneia e mucosas congestas. Achados presentes em humanos, como leucocitose, esplenomegalia e hepatomegalia, são raros em cães (Peterson e Randolph, 1982; Gray et al., 2003), contudo estavam presentes neste caso.

O diagnóstico de eritrocitose primária é dado por exclusão. Nenhum sinal de desidratação ou de algum tipo de dor ou estresse foi evidenciado no animal relatado, excluindo-se a possibilidade da eritrocitose relativa.

A eritrocitose secundária apropriada e inapropriada foi descartada com a realização de exames complementares laboratoriais e de imagem, juntamente com a dosagem de eritropoietina, que, no caso relatado, estava baixa, confirmando o diagnóstico de eritrocitose primária (Villiers e Tappin, 2012).

A terapia tradicional utilizada em animais com policitemia vera envolve flebotomias periódicas, em que são removidos 10 a $20 \mathrm{~mL} / \mathrm{kg}$ de sangue, repondo-se com solução cristaloide o volume removido (Moore and Stepien, 2001). No caso relatado, a flebotomia foi utilizada três vezes como terapia de emergência para minimizar os sintomas clínicos até estabilização do quadro clínico com a hidroxiuréia. Flebotomias seriadas podem causar deficiência de ferro, hipoproteinemia ou trombose, por isso recomenda-se uma terapia mielossupressiva (Nitshe, 2004).

A droga quimioterápica de escolha é a hidroxiuréia, a qual é bem tolerada entre os animais (Peterson e Randolph, 1982). Essa droga é um antineoplásico, que causa supressão reversível da medula óssea, inibindo a síntese de DNA (Peterson e Randolph ,1982; Gray et al., 2003), que pode ser associada a anorexia, vômito e hipoplasia medular como efeitos colaterais (Peterson e Randolph, 1982). No caso relatado, obteve-se êxito terapêutico com o uso contínuo da hidroxiureia (15 a $30 \mathrm{mg} / \mathrm{kg} / \mathrm{SID}$ ) durante oito anos, sem recidiva do quadro ou ocorrência de efeitos colaterais, em conformidade com vários casos relatados na literatura (Peterson e Randolph, 1982; Quesnel e Kruth, 1992; Gray et al., 2003).

\section{CONCLUSÃO}

A eritrocitose absoluta primária, por ser um distúrbio mieloproliferativo, quando bem conduzida demonstra um sucesso em seu tratamento, controlando a enfermidade por longo período proporcionando uma qualidade de vida satisfatória sem intercorrências relevantes.

\section{REFERÊNCIAS}

BEURLET, S.; KRIEF, P.; SANSONETTI, A. et al. Identification of JAK2 mutations in canine primary polycythemia. Exp. Hematol., v.39, p.542-545, 2011.

COMAZZI, S.; SACCHET, A.; MILANI, F.; PALTRINIERI, S.; AGNES, F. Some aspects of erythrocyte metabolism in a dog with polycythaemia vera. Vet. Rec., v.147, p.331-334, 2000.

COUTO, C.G.; BOUNDRIEAU, R.J.; ZANJANI, E.D. Tumor - associated erytrocytosis in a dog with nasal fibrosarcoma. $J$. Vet. Intern. Med., v.3, p.183-185, 1989.

FRACASSI, F.; SHEHDULA, D.; DIANA, A. et al. Primary polycythemia in a dog hypercotisolism. J. Vet. Clin. Sci., v.2, p.42-50, 2009. 


\section{Gonçalves et al.}

GRAY, H.E.; WEIGAND, C.M.; COTTRILL, N.B. et al. Polycythemia vera in a dog presenting with uveitis. J. Am. Anim. Hosp. Assoc., v.39, p.355-360, 2003.

HOLDEN, A.R. Polycythaemia vera in a dog. Vet. Rec., v.16, p.473-475, 1987.

MOORE, K.W.; STEPIEN, R.L. Hydroxyurea for treatment of polycythemia secondary to right to left shunting patent ductus arteriosus in a 4 dogs. J. Vet. Intern. Med., v.15, p.418-421, 2001.

NITSCHE, E.K. Erythrocytosis in dogs and cats: diagnosis and management. Comp. Cont. Educ. Pract. Vet., v.220, p.486-90, 2004.

PETERSON, M.E.; RANDOLPH, J.F. Diagnosis of canine primary polycythemia and management with hydroxyurea. J. Am. Vet. Med. Assoc., v.15, p.415-418, 1982.
QUESNEL, A.D.; KRUTH, S.A. Polycythemia vera and glomerulonephritis in a dog. Can. Vet. J., v.33, p.671-672, 1992.

VILLIERS, E.; TAPPIN, S. Polycythaemia. In: DAY, M.J.; KOHN, B. BSAVA Manual of canine and feline haematology and transfusion medicine. 2.ed. England: British Small Animal Veterinary Association, 2012, p.45-52.

WYSOKE, J.M.; HEERDEN, J.V. Polycythaemia vera in a dog. Tydskr. S. Afr. Vet. Assoc., v.61, p.182-183, 1990. 